\title{
Embarazo ectópico: elección de diferentes modalidades terapéuticas
}

\author{
Luis Ernesto Pérez Agudelo*
}

Los avances diagnósticos con bHCG, progesterona (P), ecografía transvaginal (ECO-TV), y laparoscopia (LPS) nos permiten detectar precozmente el $80 \%$ de los Embarazos Ectópicos (EE) aún asintomáticos. Mucho más si alertamos a las pacientes con riesgo de sufrirlo (1): EE previo (10-15\%); plastias tubáricas previas (12-15\%); patología tubárica; enfermedad de transmisión sexual o EPI (12\%); DIU (9-13\%); estrógenos postcoito (10\%); inductores ovulación (2-10\%); polución y tabaquismo.

Primero se debe confirmar embarazo con prueba en orina o sangre. En caso de embarazo normal la bHCG se duplica cada 48 horas, la $\mathrm{P}$ es $>15 \mathrm{ng} / \mathrm{ml}(>20 \mathrm{ng} / \mathrm{ml} \mathrm{si}$ inductores), y la ECO-TV muestra saco intrauterino con niveles de bHCG mayores de $1.000 \mathrm{mUI} / \mathrm{ml}$ (PRI) a las 4 semanas (2) (Tabla 1).

Tabla 1

EVOLUCION DE UN EMBARAZO NORMAL

\begin{tabular}{lcc}
-bHCG se duplica cada $48 \mathrm{hrs}$ & \\
-P $>15 \mathrm{ng} / \mathrm{ml}(>20 \mathrm{ng} / \mathrm{ml}$ si inductores) & \\
- Se correlacionan: & & \\
\hline ECO-TV & bHCG mU/ml (PRI) & Semanas \\
Saco intrauterino & $>1.000$ & 4 \\
Saco vitelino & $>7.200$ & 5 \\
Fetocardia & $>10.800$ & 6 \\
\end{tabular}

Se sospecha EE o aborto cuando el incremento de la bHCG en $48 \mathrm{hrs}$ es inferior al $66 \%$, la $\mathrm{P}<9 \mathrm{ng} / \mathrm{ml}$, y no se ve saco intrauterino (con bHCG $>1.000 \mathrm{mU} / \mathrm{ml}$ ). Algunos clínicos además descartan aborto practicando en el consultorio biopsia endometrial por aspiración en busca de vellosidades al lavado con solución salina, o por congelación. Si no es aborto se continúa pensando en EE monitorizándolo con bHCG y ECO-TV para clasificarlo y darle un adecuado tratamiento: radical si hay paridad resuelta, o conservador si hay deseos de fertilidad futura (fig.1).

Todo manejo conservador (expectante, Metrotexate, LPS, LPT) implica monitorización con bHCG a los 3, 7, y cada 7 días hasta que se negativise; y ECO-TV cada semana según el caso.

Manejo expectante. Exitoso en el 70-80\% de los casos, con resolución hasta bHCG negativa a los 20 días, promedio 3-43 (3). EE persistente $25 \%$ requiriendo MTX o intervención quirúrgica. Trompas permeables $75 \%$ (HSG). Pronóstico de $75 \%$ de embarazos intrauterinos y solo $25 \%$ de EE recurrente.

Metrotexate (MTX). $1 \mathrm{mg} / \mathrm{k}$ IM como única dosis se utiliza en el manejo conservador del $40 \%$ de los EE; igualmente efectiva a las dosis múltiples y a la incómoda aplicación intra-amniótica; sin necesidad de aplicar Leucovorin; pero contraindicado en enfermedades hema-

Unidad de Infertilidad y Endocrinología Reproductiva, Hospital Militar, Bogotá.

\author{
Figura 1 \\ MANEJO CONSERVADOR DEL EMBARAZO \\ ECTOPICO
}

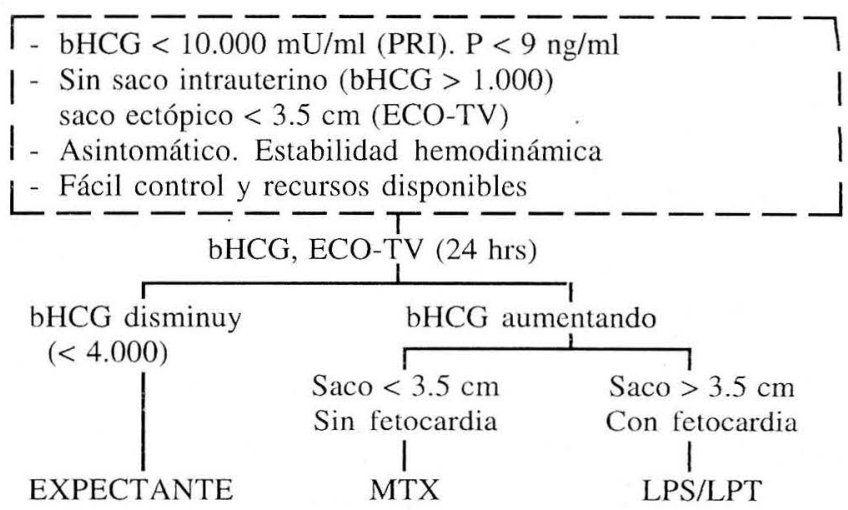

tológicas, hepato-renales y ácido péptica (4). Exito en el $65-90 \%$ con negativización de bHCG a las 2-6 semanas. EE persistente $25 \%$ requiriendo más MTX, o cirugía. Permeabilidad tubárica (al menos una) en el 77\% de los controles. Futuros embarazos intrauterinos $80 \%$ y EE recurrente en el $10 \%$ de las pacientes (5).

Laparoscopia (LPS). Salpingostomía lineal para el ampular, salpingostomía distal para el infundibular, resección segmentaria para el ítsmico e intersticial. Permite un $95 \%$ de éxitos con resolución a los 13 días. Persistencia del EE en el 5-15\% (MTX o nueva cirugía). Pronóstico de embarazos intrauterinos $57 \%$ y $10-15 \%$ de EE recurrente.

Laparotomía (LPT). Técnicas parecidas al manejo laparoscópico. Exitos en el 70-90\% y solo persistencia en el EE en $3-5 \%$ de los casos. EE recurrente en el $12 \%$ de las pacientes.

Sin lugar a duda el mayor reto del manejo conservador es mejorar la fertilidad futura de nuestras pacientes. Si actuamos precozmente en las primeras semanas del embarazo especialmente en pacientes con riesgo-, también les ayudaremos económicamente porque los costos van aumentando si se trata en forma expectante, con MTX o con cirugía.

\section{BIBLIOGRAFIA}

1. Ankum WM., Mol BWJ., Van Der Veen F., Bossuyt PMM. Risk factors for ectopic pregnancy: a meta-analysis. Fertil Steril 1996; 65: 1093.

2. Ory SJ. New options for diagnostic and treatment of ectopic pregnancy. JAMA. 1992; 267: 534.

3. Zohav E., Gemer O., Segal S. Reproductive outcome after expectant management of ectopic pregnancy. Europ. J. of Obstet. Gynecol. Reprod. Biol. 1996; 66(1): 1 .

4. Corsan GH., Karacan M et al. Identification of hormonal parameters for successful systemic single dosis methotrexate therapy in ectopic pregnancy. Human. Reprod. 1995; 10: 2719.

5. Alexander JM., Rouse DJ., Varner E., Austin JM jr. Treatment of the small ectopic pregnancy: a cost analysis of methotrexate versus laparoscopy. Obstet. Gynecol. 1996; 88(1): 123. 